\title{
A flâneuse na literatura brasileira: espaços e temporalidades contestados
}

\author{
The Flâneuse in Brazilian Literature: Contested Spaces and Temporalities \\ La flâneuse en la literatura brasileña: espacios y temporalidades contestados
}

Sara Brandellero*

\begin{abstract}
Resumo
A questão do espaço, e sua "produção", conforme Lefebvre (1974), vem se revelando uma rica área de pesquisa para os estudos literários, assim como as questões ligadas à mobilidade em suas diferentes realidades: de experiências de migração e diáspora a trânsitos urbanos, para citar alguns exemplos. Nesse contexto, a figura do flâneur, intrinsicamente ligada às experiências e representações da modernidade urbana, tem atraído considerável interesse crítico. Em geral, pouco explorada ainda é a figura de seu equivalente feminino, a flâneuse, pois, como bem observa Wolff (1985), a experiência da modernidade tem sido, em grande parte, narrada sob um ponto de vista predominantemente masculino. A partir do conto "Amor", de Clarice Lispector (1960/1998), e o texto "Um corpo negro pelado", de Miriam Alves (2014), este artigo discute como esses textos parecem dialogar com o paradigma da mobilidade moderna, analisando personagens femininas em trânsito na literatura brasileira contemporânea escrita por mulheres como tentativas de repensar a experiência desta mobilidade, agora como um ato político e de busca de empoderamento feminino.
\end{abstract}

Palavras-chave: flâneur, flâneuse, mobilidade, gênero, literatura.

\begin{abstract}
The question of space and its "production", following Lefebvre (1975), has emerged as a fertile field of enquiry for literary studies, also when related to question of mobility in different contexts: from experiences of migration and diaspora to urban transits, to cite a few. In this context, the figure of the flâneur, intrinsically connected to experiences and representation of urban modernity, has attracted considerable critical attention. However, little attention has been awarded to its female counterpart, the flâneuse, because, as Wolff (1985) rightly observes, the experience of modernity has been in great part narrated from a male perspective. Starting with the short story "Amor" [Love] by Clarice Lispector (1960/1998), and the text "Um corpo negro pelado" [A naked black body] by Miriam Alves (2014), the article will discuss how these texts seem to dialogue with this paradigm of modern mobility. It will consider how female mobility in Brazilian literature written by women express attempts to rethink mobility as a political act and as a search for female empowerment.
\end{abstract}

Keywords: flâneur, flâneuse, mobility, gender, literature.

\section{Resumen}

La cuestión del espacio, y su "producción", según Lefebvre (1975), se ha revelado una rica área de investigación para los estúdios literários, así como las cuestiones ligadas a mobilidade en sus distintas realidades: desde las experiencias de migración y diaspora a transitos urbanos, para citar algunos ejemplos. En este contexto, la figura del flâneur, intrinsicamente ligada a las experiencias y representaciones de la modernidad urbana, ha atraido considerable interés crítico. En geral, poco estudada ainda ha sido la figura de su equivalente feminino, la flâneuse, pues, como bien observa Wolff (1985), la experiencia de la modernidade ha sido, en grande parte, narrada desde un punto de vista predominantemente masculino. A partir del cuento "Amor", de Clarice Lispector (1960/1998), y del texto "Um corpo negro pelado" [Un cuerpo negro desnudo] de Miriam Alves (2014), este artigo estuda de que forma parecen dialogar con este paradigma de la mobilidad moderna. Discutirá de que manera podemos pensar mujeres en transito en la literatura brasileña contemporanea escrita por mujeres como tentativas de repensar la experiencia de esta mobilidad, ahora como un acto político y de busca de empoderamento feminino.

Palabras-clave: flâneur, flâneuse, mobilidade, género, literatura.

\footnotetext{
*Universidade de Leiden, Leiden, Holanda. Dorcid.org/0000-0003-3937-0239. E-mail: s.l.a.brandellero@ hum.leidenuniv.nl
} 
Este artigo propõe uma análise comparativa do conto "Amor" da coletânea Laços de família (1960), de Clarice Lispector, e do texto contemporâneo intitulado "O corpo negro pelado", da escritora afro-brasileira Miriam Alves (2014), lidos através do conceito de mobilidade. Escritos com mais de 60 anos de diferença um do outro, ambos os textos se comprometem a pensar a mobilidade da mulher na sua relação com o espaço público urbano e, consequentemente, refletir sobre as políticas da mobilidade, como dinâmicas de poder, que se manifestam quando a mulher transita entre o público e o privado, sendo este último o espaço ao qual ela tradicionalmente foi relegada. Ambos os textos recuperam um motivo narrativo que, recorrentemente, capta a experiência da modernidade urbana - o do encontro fugaz entre estranhos nas ruas da cidade -, mas o reelaboram para visualizar e imaginar práticas de espaços tradicionalmente negadas e contestadas. Desta forma, problematizam o que Lefebvre define como o "direito à cidade" (1968/1996) do ponto de vista da experiência feminina.

Através de uma leitura comparativa, este artigo visa entender o que os contos nos dizem sobre a condição feminina em dois momentos diferentes: o primeiro, problematizando a experiência da modernidade desde uma perspectiva de gênero; e o segundo, repensando a mobilidade feminina desde uma clara perspectiva de raça, refletindo a emergência das discussões sobre raça e etnia das últimas décadas.

Nas últimas décadas do século XX, o conceito de espaço surgiu como paradigma para entender a complexa interligação da experiência humana com o meio em que ela se desenrola. A chamada "virada espacial", e seu foco em noções como lugar, paisagem, território, revelou-se uma rica área de pesquisa para os estudos literários e culturais - uma linha fértil interpretativa impulsionada pela escrita de Lefebvre (1974), Cosgrove (1984), Moretti (1998), Harvey (2008), Certeau (1980), entre outros. Mais recentemente, a importância das experiências de deslocamento para o entendimento do mundo contemporâneo tem levado à consolidação do paradigma da mobilidade como uma produtiva chave de leitura no contexto da "virada das novas mobilidades", na esteira de escritos pioneiros como os de Sheller e Urry (2004) e Cresswell (2006). Refletindo sua presença marcante e muitas vezes polarizadora nos debates sócio-políticos contemporâneos, a mobilidade como discurso e representação tem convocado crescente interesse crítico também no âmbito literário. Pensemos em questões ligadas a deslocamentos em grande escala - como a migração nacional e transnacional ou o movimento mundial de refugiados -, ou em escala local, do cotidiano, como a viabilidade de nossos centros urbanos e dos transportes públicos.

O mundo tem sido marcado pelo movimento de pessoas em escala sem precedentes, com o maior índice de pessoas forçadamente deslocadas na história a níveis de 68,5 milhões em 2018 (Robila, 2018). O Brasil tem sido um centro de migração em escala global - com mais de 700.000 imigrantes registrados em 2017 (Wejsa e Lesser, 2018). A literatura brasileira tem refletido cada vez mais visivelmente a centralidade da mobilidade nas vivências do mundo contemporâneo, com a criação de obras como as que revisitam a história de migração no Brasil - como Relato de um certo oriente, de Milton Hatoum (1999), e A chave da casa, de Tatiana Salem Levy (2007) - ou apresentam uma perspectiva contemporânea de emigração brasileira como Estive em Lisboa e lembrei de você, de Luiz Ruffato (2009). Nesse contexto, migrantes, personagens diaspóricas e exilados têm povoado também as páginas da crítica literária recente em números consideráveis (Tonus, 2012; Chiarelli e Oliveira Neto, 2016).

Entre as figuras definidas pela mobilidade, a do flâneur, intrinsecamente ligada em sua origem às experiências e representações da modernidade urbana, tem inspirado uma multiplicidade de leituras. Pouco explorada e discutida ainda é a sua contrapartida feminina, pois, como bem observa Wolff (1985), a experiência da modernidade tem sido, em grande parte, narrada desde um ponto de vista predominantemente masculino.

Este artigo se concentra, no entanto, especificamente na questão de gênero, pensando a realidade da mobilidade feminina, e toma como ponto de partida um conceito de mobilidade, entendida como concentração de forças sociais e políticas. Seguindo a argumentação do geógrafo cultural Tim Cresswell (2006), como, onde e quando as pessoas se deslocam é tão significativo quanto onde vivem em termos de diferenciação social. De fato, a discussão aqui parte de um conceito de mobilidade, um fenômeno geográfico inserido em diferentes dinâmicas 
de poder (Cresswell, 2006, p. 20). E se, seguindo Sheller e Urry, a mobilidade é sempre "localizada e materializada" (2004, p. 210), pretendo discutir como a tradicional figura do flâneur tem sido retrabalhada e problematizada a partir de uma perspectiva de gênero e raça no contexto brasileiro. Para tanto, este estudo lança mão da discussão proposta por Martha Meskimmon sobre a "estética do pedestre" ao enfatizar a experiência do corpo no espaço numa perspectiva interseccional com questões de gênero e raça.

O conceito de pedestre diz respeito à condição de conhecer o espaço através do corpo... Em termos conceituais, o pedestre difere do flâneur em sua conexão com o lugar e a fisicalidade. Ela (a pedestre) tem um corpo e uma situação no espaço, mas não no sentido de essência biológica. O corpo neste contexto não é uma certeza biológica ou determinante, mas o lugar em que biologia e produções culturais se cruzam e produzem um senso de identidade e de subjetividade. O corpo da pedestre e sua incorporação são eles mesmos um espaço que permite uma interação engajada com o mundo à sua volta. Ela não é um olho desencorpado como o flâneur ideal que vagueia pela cidade "invisivelmente" e sem poder ser alcançado, mas um participante consciente da cidade. Ela percebe as fronteiras existentes a partir do corpo e rejeita a fronteira do privilégio do flâneur e a noção de uma cidade utópica e unificada" (Meskimmon, 1997, p. 21 apud Carrera Suárez, 2015, p. 865, tradução nossa).

\section{A flânerie}

A figura do flâneur, consagrada por Baudelaire e mais tarde abordada em termos teóricos por Benjamin (1973), é o artista e cronista das ruas, invariavelmente um homem sem prementes preocupações financeiras e com tempo de sobra para perambular livremente pelas ruas da metrópole, perscrutando (como observador anônimo e distante) o espetáculo do cotidiano da cidade. Benjamin lançou mão de uma metáfora associada ao exercício de exploração de campo científica quando aludiu ao flâneur como uma espécie de "botânico das calçadas" (1973, p. 36), descobridor e catalogador metafórico do universo das ruas e galerias da rede urbana. Como afirma Schulte Nordholt (2008), a famosa definição do flâneur cunhada por Benjamin (amiúde erroneamente atribuída ao próprio Baudelaire) capta a realidade deste tipo social. Com efeito, já desde antes de 1850, anterior a Baudelaire, portanto, a flânerie tinha se tornado uma "atitude", "um estilo de vida" (Benjamim, 1973, p. 67) cujo praticante seria descrito em numerosos textos na virada do século XIX.

De acordo com Priscilla Parkhurst Ferguson (1994), a primeira referência à figura do flâneur aparece num panfleto anônimo de 1806 intitulado Le flâneur au salon ou Mr Bon-Homme. Este foi o primeiro de numerosas outras publicações, tais como o livreto humorístico Physiologie du flâneur de Louis Huart (1841), que capturaram a emergência do tipo burguês desconectado de qualquer obrigação social (Ferguson, 1994, p. 26): a flânerie requer "a cidade e suas massas, mas o flâneur permanece desvinculado de ambos" e a companhia feminina (com sua suposta obsessão com as compras) seria uma distração inoportuna ao prazer de apreender o espetáculo da cidade em sua totalidade (Ferguson, 1994, p. 27).

De fato, com relação ao flâneur, a sua contrapartida feminina permanece quase totalmente invisível como sujeito praticante do espaço da cidade, raramente passando de um mero objeto do olhar masculino, refletindo uma dinâmica desigual com relação ao "direito à cidade" (Lefebvre, 1968/1996), amiúde apontado pela crítica feminista. Janet Wolff $(1985$, p. 37) salienta o fato de a modernidade ter sido registrada particularmente no âmbito do espaço público (ruas, calçadas, cafés etc.), sendo esse território de prerrogativa masculina. Ilustração disso é o fato de que o que assegurou à escritora George Sand a possibilidade de experimentar a vivência do flâneur e explorar as ruas parisienses foi a estratégia por ela adotada de se disfarçar de menino (Wolff, 1985, p. 41). Nas divisões de gênero estabelecidas, em contraste com a mobilidade irrestrita e indolente do flâneur, que passava a cristalizar uma nova e sofisticada relação com a cidade, era sintomático que a mobilidade das mulheres das classes trabalhadoras, ou mulheres de classe média, principalmente solteiras, na sociedade vitoriana inglesa, era algo sujeito a controles e restrições (Wilson, 1992, p. 90-93). 
As problemáticas de gênero à base da política de mobilidade urbana que subsistem até os dias de hoje parecem ser eloquentemente confrontadas nos dois contos escolhidos aqui para análise. De fato, o destaque dado em ambos os contos à figura feminina em movimento pela cidade possibilita uma leitura comparativa embasada no "direito à cidade" feminino. Através destas reconfigurações da flâneuse, as limitações a este direito são desvendadas. No primeiro conto, problematiza-se uma visão otimista da experiência feminina na modernidade dos anos 1960, antecipando, desde uma perspectiva ficcional, muitos dos debates propagados pela segunda onda feminista (Alonso, 2000, p. 74). O segundo conto aponta para a reivindicação ao espaço físico da cidade, e à sua representação na literatura, por parte do sujeito afro-brasileiro. Espelhando a emergência cada vez mais significativa nos últimos anos de movimentos de ativismo cultural afro-brasileiros, apoiados por políticas governamentais de inclusão dos governos Lula e Dilma, o conto articula uma reivindicação feminina de maneira interseccional à questão de raça. Antes de abordar o conto de Miriam Alves, na parte deste artigo que segue, pretende-se fazer uma análise do conto "Amor", da coletânea Laços de família, visando entender de que maneira a mobilidade da protagonista dialoga com a convenções de representação literária tradicionalmente associadas ao flâneur, problematizando, assim, a relação feminina com o espaço público.

\section{Saindo dos trilhos}

Em sua análise sobre Laços de família, a crítica Pazos Alonso observa como ela articula em microescala as frustrações de mulheres impedidas de buscar sua realização fora do âmbito doméstico, expressando, através do poder da imaginação, muitas discussões que seriam conceptualizadas do ponto de vista sociológico no clássico da literatura feminista A mística feminina de Betty Friedan, publicado em 1963 (Alonso, 2000, p. 73). Os contos dão voz às angústias íntimas e frustrações (conscientes ou não) de mulheres que, se não aflitas por grandes preocupações financeiras, veem seu horizonte de realizações delimitado pelas obrigações socialmente impostas como esposas e mães.

A questão das relações de gênero tem instigado múltiplas leituras críticas da coletânea de Clarice, como a análise sobre gênero e violência, de Marta Peixoto (1994), e das relações familiares, de Alonso (2000). Este estudo pretende verificar como esta problematização se articula em "Amor" por meio de uma experiência de deslocamento urbano da protagonista Ana, dona de casa, que retorna para casa de bonde num final de tarde após fazer compras na cidade. Ao acompanhar a protagonista em suas deambulações, Clarice problematiza o lugar ocupado pela mulher dentro da modernidade e em sua relação entre os espaços públicos e privados.

Clarice constrói uma narrativa em que o olhar tradicionalmente "desencorpado" do flâneur (Carrera Suárez, 2015) dá lugar a um olhar assumidamente feminino. Nesse sentido, levanta-se uma hipótese de leitura que entende o conto como uma metáfora narrativa - uma configuração ficcional - da impossibilidade imposta à mulher, no contexto patriarcal, de incorporar o tipo benjaminiano do botânico das ruas, como pretendo argumentar a seguir.

Sentada num bonde, com a sacolinha de rede de tricô aos pés, apesar de ocupar o espaço público das ruas (situação enfatizada também pelo contexto de transporte público em que ela se encontra), Ana aparece distante da realidade à sua volta. Uma narrativa em discurso indireto livre se delonga, na abertura do conto, sobre detalhes da "aparência harmoniosa" da vida doméstica, sobre as memórias de Ana de sua vida de solteira, com sua "íntima desordem", sua relação com os filhos, suas frustrações mal sufocadas (Lispector, 1998, p. 20).

A condição psicológica de Ana ao embarcar no bonde fica aparente desde os primeiros momentos do seu deslocamento pela cidade:

Um pouco cansada, com as compras deformando o novo saco de tricô, Ana subiu no bonde. Depositou o volume no colo e o bonde começou a andar. Recostou-se então no banco procurando conforto, num suspiro de meia satisfação. Os filhos de Ana eram bons, uma coisa verdadeira e sumarenta. Cresciam, tomavam banho, exigiam para si, malcriados, instantes cada vez mais completos (Lispector, 1998, p. 19). 
Apesar de se encontrar fisicamente afastada do âmbito doméstico em suas deambulações pela cidade, fica claro o fato de Ana estar a ele mentalmente acorrentada. De fato, o movimento retrospectivo operado pela narrativa em flashback com que o conto abre contrasta simbolicamente o movimento dianteiro do bonde e sublinha a imobilidade real (e psicológica) da personagem, que se encontra inteiramente desconectada de qualquer atração ou distração que a cidade possa oferecer.

Tal caracterização rejeita a aproximação muitas vezes estabelecida do bonde com o processo de espectacularização da cidade moderna, como espécie de cinema em movimento. Rosenthal observa que "poderíamos considerar o bonde como o meio de transporte representativo do flâneur latinoamericano do século $\mathrm{XX}$, que observa a cidade de um palco itinerante que traz paralelos com a experiência do espectador da sala de cinema" (Rosenthal, 2016, p. 170, tradução nossa). Dessa forma, parece significativo que referências ao deslocamento de Ana ocorram apenas num nível metafórico. Isso acontece precisamente quando ela reflete sobre os percursos que a vida lhe apresentou: "Por caminhos tortos, viera a cair num destino de mulher, com a surpresa de nele caber como se o tivesse inventado" (Lispector, 1998, p. 20). Na realidade, a sua condição no presente está intrinsecamente espelhada no percurso inevitavelmente definido dos trilhos do bonde, como se neles estivessem impressas as restrições impostas à mobilidade e à liberdade de escolha de Ana.

Clarice constrói uma rede metafórica ligada à mobilidade de Ana que conduz a narrativa ao momento em que a protagonista vivencia uma crise emocional e psicológica provocada pela desintegração do equilíbrio que criou para si. Um vacilo repentino do bonde em seus trilhos marca o instante em que, para Ana, fragmenta-se a ordem (embora precária) estabelecida. A sequência ordenada das suas tarefas diárias vê-se de repente abalada, deixando Ana literalmente desnorteada pelas ruas da cidade. Com efeito, a crise se precipita quando, em seguida, Ana avista um homem cego, parado no ponto do bonde mascando chiclete:

Então ela viu: o cego mascava chicles... Um homem cego mascava chicles. Ana ainda teve tempo de pensar por um segundo que os irmãos viriam jantar - o coração batia-lhe violento, espaçado. Inclinada, olhava o cego profundamente, como se olha o que não nos vê. Ele mastigava goma na escuridão. Sem sofrimento, com os olhos abertos (Lispector, 1998, p. 21).

O encontro fortuito aqui descrito, catalisador de uma crise na protagonista, remete a um motivo recorrente na literatura da modernidade, sobretudo em contexto urbano, que pretende captar a realidade fragmentada e efêmera do mundo moderno (Vila-Cabanes, 2018, p. 11). A poesia de Baudelaire (e sua configuração da experiência do flâneur) é o exemplo mais frequentemente associado à emergência dessa feição tida como estrutural da experiência na cidade moderna (VilaCabanes, 2018, p. 212), sendo o canônico poema A una passante um de seus exemplos mais citados. Vejamos um extrato do poema baudelairiano na tradução de Ivan Junqueira:

Pernas de estátua, era-lhe a imagem nobre e fina.

Qual bizarro basbaque, afoito ou the bebia

No olhar, céu lívido onde aflora a ventania.

A doçura que envolve e o prazer que assassina (Baudelaire, 1857/1985, p. 361).

A experiência do choque que caracteriza a vivência na cidade moderna, e que Benjamin (1973; 1999) vê refletida na poesia de Baudelaire, articula-se aqui através da experiência do flâneur e seu encontro fortuito com uma mulher andando na rua. No poema, um olhar masculino visualiza o corpo feminino através de imagens que evocam prazer, mas também tentação, perigo e morte - perpetuando uma demonização da sexualidade feminina arraigada no imaginário patriarcal. O poder real está no domínio do flâneur (masculino), fato que é reforçado pela visualização do corpo feminino avistado no meio da multidão da cidade através da metonímia das "pernas de estátua" - imagem fragmentada de um corpo feminino paradoxalmente estático e objetificado, na qual a sua falta de agenciamento fica materializada.

Clarice retoma o motivo literário do encontro fugaz entre desconhecidos na cidade moderna, mas parece reelaborá-lo a fim de pôr em cheque as dinâmicas de poder nele tradicionalmente imbricadas. Conforme lembra Griselda Pollock (1988, p. 70), uma prerrogativa tradicional do flâneur nunca questionada é a de ser dono do "olhar", e no encontro fortuito que se dramatiza 
em "Amor", Ana parece, de início, ser detentora do poder de "ver" o outro, já que é ela a avistar o "homem cego". Porém, na política do olhar que naquele momento se articula, o poder implícito de Ana é circunscrito pela cegueira do homem: "Inclinada, olhava o cego profundamente, como se olha o que não nos vê" (Lispector, 1998, p. 21). Ademais, o mascar contínuo do chiclete parece reforçar o fato de que o poder do olhar que Ana detém é ilusório: "O movimento da mastigação fazia-o parecer sorrir e de repente deixar de sorrir, sorrir e deixar de sorrir - como se ele a tivesse insultado" (Lispector, 1998, p. 21).

De fato, a quebra da ordem (superficial) da existência regrada da protagonista ocorre a partir desse encontro casual, em que se evidencia a impossibilidade da personagem de controlar a realidade em sua volta, ficando aparente a impossibilidade de transgredir as fronteiras das convenções de gênero. A mesma cidade por que Ana antes percorria trajetos familiares passa a ser repentinamente um espaço desconhecido e ameaçador. Desnorteada pela postura imperturbável do homem cego, Ana perde o ponto do bonde. Com dificuldade para se localizar, acaba finalmente por entrar no Jardim Botânico. Se o flâneur é o observador atento e anônimo do espetáculo da cidade moderna em rápida e constante transformação, é significativo que o olhar de Ana não seja o olhar de quem categoriza o mundo em volta, típico do botânico das ruas. Com efeito, ao transpor o portão do Jardim do Botânico fica amplificado o espanto de Ana, que é de quem ali identifica uma pulsão desafiadora:

Depositou os embrulhos na terra, sentou-se no banco de um atalho e ali ficou muito tempo... Inquieta, olhou em torno. Os ramos se balançavam, as sombras vacilavam no chão. Um pardal ciscava na terra. E de repente, com mal-estar, pareceu-lhe ter caído numa emboscada. Fazia-se ali um trabalho secreto do qual começava a se aperceber (Lispector, 1998, p. 24).

Se, no âmbito da cidade, não há espaço evidente para a contrapartida feminina do flâneur, o mesmo parece acontecer no entrelugar entre natureza e cidade que o Jardim Botânico representa. No entanto, a natureza artificialmente controlada e circunscrita pelas grades do Jardim Botânico, mas aparentemente prestes a explodir, parece espelhar a realidade da protagonista - marcada pelas limitações a ela imposta e na qual ainda se reconhece a potencialidade de transgressão. O movimento da natureza que Ana percebe em sua volta - o balanço dos ramos, o vacilo das sombras - sugere a potencialidade de transformação latente. Assim, na meia luz do fim de tarde, é neste ambiente (e não nas ruas da cidade) de uma natureza que não pode ser inteiramente controlada que Ana parece identificar e ver refletida sua própria experiência. Nessa experiência também reside a invisibilidade dessa caminhante urbana, parece. Com efeito, lemos sobre sua partida do Jardim Botânico: "Sacudiu os portões fechados, sacudia-os segurando a madeira áspera. $\mathrm{O}$ vigia apareceu espantado de não a ter visto" (Lispector, 1998, p. 26).

Nada é dito a seguir sobre o trajeto que Ana percorre até em casa, não há observação dos tipos que transitam pelas ruas. Apenas sabemos que Ana chega afobada, buscando recuperar a segurança do espaço asséptico de seu apartamento no nono andar - bem afastado do nível da rua. O desfecho do conto ilustra o retrair-se de Ana para a ordem repressora do lar: "penteavase agora diante do espelho, por um instante sem nenhum mundo no coração. Antes de se deitar, como se apagasse uma vela, soprou a pequena flama do dia" (Lispector, 1998, p. 29). A imagem de Ana aqui sugere uma quase imobilidade da personagem dentro das paredes do lar, sublinhando as limitações a ela impostas em seu "direito à cidade".

\section{A mulher negra na rua}

Se o conto de Clarice aponta para uma revisão da flânerie (e suas limitações), pensando a condição feminina que existe por trás do aparente conforto doméstico da modernidade, o texto da autora afro-brasileira Miriam Alves reflete um momento de reinvidicação da visibilidade do corpo feminino no espaço público num contexto histórico e social marcado por recentes avanços em termos de políticas sociais. Ativista importante, a partir da década de 1980, e membro do coletivo Quilombhoje Literatura, responsável pela publicação dos Cadernos Negros, coletâneas de poesia e contos de autoria afro-brasileira, é nesses mesmos Cadernos que a própria Alves 
estreia em 1982 (Literafro, 2019). O texto "Um corpo negro pelado", apresentado pela autora no auditório do Ministério da Cultura (Minc) em São Paulo em 2013, e publicado posteriormente em Modo de usar \& co. (Alves, 2014), dá seguimento à sua defesa do sujeito negro ao configurar sua encarnação da figura da flâneuse através do que a crítica fotográfica Martha Meskimmon definiu como a "estética do pedestre", o pedestrianism (Carrera Suárez, 2015).

O texto transita entre crônica e ficção e descreve o encontro fortuito entre duas mulheres nas ruas noturnas de São Paulo. Uma voz assumidamente feminina em primeira pessoa descreve o momento em que avista uma mulher negra nua desfilando "majestosamente" numa avenida movimentada da metrópole. A visão da anônima passante negra impulsiona a narradora a repensar sua própria relação com o corpo, levando-a a redescobrir o orgulho de sua própria negritude. Nesse sentido, os diferentes contextos do espaço urbano em que as personagens dos dois textos são visualizadas são reveladores. Clarice visualiza Ana sentada num bonde, representação de um espaço público e de uma "viagem" comunitária. Através dessa escolha narrativa, a autora conecta de imediato a experiência da mulher com o contexto social do patriarcado em que se inscreve, e os trilhos do bonde enfatizam o destino traçado que Ana segue dedicadamente. Já no texto de Alves, coloca-se, em primeiro plano, a figura da pedestre feminina e, assim, uma subjetividade que, diferentemente de Ana, é consciente do lugar que quer ocupar no contexto social contemporâneo.

É assim que o motivo literário do encontro fugaz, central no desenrolar da narrativa no conto clariceano, surge no texto de Alves numa reformulação que defende a visibilidade da mulher negra e o poder implícito no seu poder de olhar. Em "Amor" evidenciava-se a invisibilidade social de Ana pela sua própria invisibilidade real, já que ela passava despercebida tanto pelo homem cego cuja presença leva à quebra do dia a dia ordenado da protagonista quanto pelo vigia do jardim botânico, que toma consciência de sua presença apenas depois de ouvir o sacudir do portão do jardim, na saída de Ana, rumo à casa. Dessa forma, no contexto social e histórico que fundamenta o conto de Clarice, ficam evidentes as limitações impostas às mulheres de serem detentoras do olhar. Alves, no entanto, parece propositalmente recriar o motivo do encontro fugaz baudelairiano com uma passante anônima, só que aqui o corpo em movimento tem consciência do espaço que ocupa e quer contestar. Numa perspectiva interseccional, Alves reivindica o direito à mobilidade da mulher no espaço público da rua juntamente com a consciência de raça. Ao visualizar o corpo negro em movimento na rua à noite, enfatiza-se o agenciamento que a pedestre se outorga:

Um corpo de uma mulher negra nua passeando em plena avenida movimentada de um bairro em São Paulo às 23 horas e 30 minutos, entre restaurantes populares e posto de gasolina e dois prédios apartamentos residenciais... O meu olhar refletia espanto, encanto e um traço de perplexidade, nos olhos dela certezas, tranquilidade em contraste com um leve sorrir talvez sarcástico. Ao me distanciar, alguns passos, eu ousei olhar para trás e vi as pernas roliças e a bunda carnuda arredonda se movendo no caminhar como ondas oceânicas de superfície, ondulando, ondulando. E assim a mulher se foi na noite ondulando sua vestimenta pele natural, e eu me fui, na noite com o meu corpo acobertado por tecidos transformados em roupas que com a justificativa de me proteger me aprisiona (Alves, 2014, s.p.).

Alves recria aqui um encontro fugaz que ecoa o do poema baudelairiano, mas a mulher deixa de ser associada ao imaginário da morte (como em Baudelaire) e está desvinculada do espaço doméstico (como no caso do conto de Clarice). Além disso, a dinâmica do olhar entre o flâneur anônimo e o sujeito feminino está suplantado por um olhar feminino que, inicialmente intimidado, em seguida se identifica com o sujeito empoderado negro, também feminino: "quando os nossos caminhos se entrecruzaram os olhares por instante se encontraram" (Alves, 2014, s.p.). O texto subverte o jogo de poder tradicional, pois é a mulher que detém o olhar de "certezas" e "tranquilidade". Ademais, seguindo as formulações de Meskimmon, a mulher andante é "participante consciente da cidade" (Carrera Suárez, 2015, p. 21) não apenas contestando o seu direito de ocupar o espaço público da rua, mas como corpo feminino negro que se quer visível e defende para si o direito à cidade noturna (são 23h30): um tempo-espaço tradicionalmente associado a maiores riscos para qualquer mulher sozinha que nele queira se aventurar. 
Nesse espaço noturno, Alves contrapõe uma imagem ordenada, regimentada até, da cidade, captada pela referência aos "postes enfileirados dos dois lados da rua", com a visão do corpo feminino que passa tranquilamente, e cujo "trajeto não seria interrompido pelos olhos assustados, ou atos violentos de ninguém" (Alves, 2014, s.p.). Na visualização da mobilidade feminina articulada por Alves, a justaposição tradicional, cara ao patriarcado, do espaço da cultura (associado à ordem) ao espaço da natureza fica subvertida. A epifania apenas vislumbrada pela protagonista do conto clariceano e refletida na desordem contida do Jardim Botânico torna-se completa no texto de Alves. As associações ao espaço oceânico e sua superfície em movimento convocam a importância da memória e da consciência da ancestralidade nesse processo. Assim, o fato de Alves evocar, ao final do texto, o orixá Exu, entidade ligada ao movimento, à comunicação, bem como à sexualidade, através da figura feminina, é sintomático desse processo de libertação possibilitado pela (re)descoberta do poder da memória ancestral e da consciência de gênero: "a mulher nua tranquila em seu caminhar parecia uma entidade enviada pelo Orixá Exu, com luzes refletidas na pele noite como olhos indicando caminhos, desvelando os vários signos de palavras racistas, machistas e outras que cobrem os nossos corpos negros como vestimentas eternas e naturais" (Alves, 2014, s.p.).

\section{Conclusão - (I)mobilidades noturnas}

A título de conclusão, é revelador como, por meio da temática da mobilidade, os dois textos refletem sobre a condição feminina em momentos históricos-sociais distintos da realidade brasileira. Ao atualizar um motivo literário vinculado à modernidade urbana, eles dialogam com o tipo urbano encarnado pelo flâneur a partir da relação do sujeito feminino com a mobilidade e o espaço público, no qual ela foi tradicionalmente marginalizada. Nesse sentido, destaca-se o fato de que em ambos os textos aparece o cronotipo da noite, através do qual a relação da mulher com o espaço da cidade parece amplificada. Com efeito, em "Amor", a personagem busca refúgio da noite reintegrando-se à ordem doméstica convencional que ela conhece, no papel ensaiado que dela se espera de esposa e mãe. Já o texto de Alves demonstra a possibilidade de imaginar a mulher não apenas na rua, mas defendendo para si o "direito à cidade" ao pisar num espaço-tempo (a cidade à noite) a ela amiúde negado. Escrito num contexto sócio-histórico de avanços em inclusão social, o texto de Alves discorre sobre a mobilidade noturna da mulher negra ao imaginar um Brasil em que outras vozes são ouvidas e outros corpos ficam mais visíveis. A nudez do corpo negro feminino como espaço de memória diaspórica - tal como sugerido pela referência às ondas oceânicas - se instaura com sua "estética da pedestre", seguindo Meskimmon (Carrera Suárez, 2015), querendo ser inscrita na geografia da cidade. No encontro fortuito que ali se dramatiza, a própria figura da flâneuse invisível é questionada. Com efeito, a referência à "pele noite" da andarilha anônima projeta e materializa no próprio corpo da mulher sua realidade de "pedestre", de subjetividade que contesta seu lugar nestes espaços e temporalidades tradicionalmente a ela negados.

\section{Referências}

ALONSO, Cláudia Pazos (2000). Family ties and déjà-vu in Laços de Família. In: ALONSO, Cláudia Pazos; WILLIAMS, Claire (Ed.). Closer to the wild heart. Oxford: Legenda.

ALVES, Miriam (2014). O corpo negro pelado. Modo de Usar \& CO., 19 jan. Disponível em: https:// bit.ly/362PqOC. Acesso em: 30 nov. 2017.

BAUDELAIRE, Charles (1857/1985). As flores do mal. Tradução de Ivan Junqueira.. Rio de Janeiro: Nova Fronteira. Edição bilíngue

BENJAMIN, Walter (1973). Charles Baudelaire: a lyric poet in the era of high capitalism. Londres: Verso.

BENJAMIN, Walter (1999). On some motifs in Baudelaire. In: BENJAMIN, Walter. Illuminations. Edição e introdução de Hannah Arendt. Prefácio de Leon Wieseltier. Tradução de Harry Zorn. Londres: Pimlico. 
CARRERA SUÁREZ, Isabel (2015). The stranger flâneuse and the aesthetics of pedestrianism: writing the post-diasporic metropolis. Interventions, v. 17, n. 6, p. 853-865, 7 jan.

CERTEAU, Michel de (1980). L'invention du cotidien. Paris: Gallimard.

CHIARELLI, Stefania; OLIVEIRA NETO, Godofredo de (2016) (Org.). Falando com estranhos: o estrangeiro e a literatura brasileira. Rio de Janeiro: 7 Letras.

COSGROVE, Dennis (1984). Social formation and symbolic landscape. Londres: Croom Helm.

CRESSWELL, Tim (2006). On the move: mobility in the modern world. New York; Abingdon: Routledge.

FERGUSON, Priscilla Parkhurst (1994). The flâneur on and off the streets of Paris. In: TESTER, Keith (Ed.). The flâneur. Londres: Routledge. p. 22-42.

HARVEY, David (2008). The right to the city. The New Left Review, n. 53, p. 23-40, set./out.

LEFEBVRE, Henry (1968/1996). The right to the city. In: KOFMAN, Eleonore; LEBAS, Elizabeth (Ed.). Writings on cities. Cambridge, MA: Blackwell, p. 147-159.

LEFEBVRE, Henry (1974). La production de l'espace. Paris: Anthropos.

LISPECTOR, Clarice (1960/1998). Laços de família. Rio de Janeiro: Rocco.

LITERAFRO (2019). Miriam Alves. Disponível em: http://www.letras.ufmg.br/literafro/autoras/348miriam-alves. Acesso em: 14 mar. 2019.

MORETTI, Franco (1998). An Atlas of the European Novel 1800-1900. Londres: Verso.

PEIXOTO, Marta (1994). Passionate fictions. Minneapolis; London: University of Minnesota Press.

POLLOCK, Griselda (1988). Vision and difference. Londres: Routledge.

ROBILA, Mihaela (2018). Refugees and social integration in Europe. New York: Undesa. Disponível em: https:// bit.ly/2tgntpy. Acesso em: 22 fev. 2019.

ROSENTHAL, Anton (2016). The streetcar in the urban imaginary of Latin America. Journal of Urban History, v. 42, n. 1, p. 162-179, jan.

SCHULTE NORDHOLT, Annelies (2008). Georges Perec: topographies parisiennes du flâneur. Revue Électronique de Littérature Française, v. 2, n. 1, p. 66-86, 19 mar.

SHELLER, Mimi; URRY, John (Ed.) (2004). Tourism mobilities: places to play, places in play. London; New York: Routledge.

TONUS, José Leonardo (2012). O imigrante na literatura brasileira: instrumentalização de uma figura literária. In: DALCASTAGNÈ, Regina; MATA, Anderson Luís Nunes da (Org.). Fora do retrato: estudos de literatura brasileira contemporânea. Vinhedo: Horizonte. p. 93-101.

VILA-CABANES, Isabel (2018). The flaneur in nineteenth-century british literary culture: the worlds of London unknown. Newcastle: Cambridge Scholars Press.

WEJSA, Shari; LESSER, Jeffrey (2018). Migration in Brazil: the making of a multicultural society. The Online Journal of Migration Policy Institute, Washington, 29 mar. Disponível em: https://bit.ly/2uF3yRv. Acesso em: 7 mar. 2019.

WILSON, Elizabeth (1992). The invisible flâneur. New Left Review, n. 191, p. 90-110, jan./fev.

WOLFF, Janet (1985). The invisible flâneuse: women and the literature of modernity. Theory, Culture $\mathcal{E}$ Society, v. 2, n. 3, p. 37-46, nov. 